\title{
Analysis of Adsorption Technologies of Water and Wastewater Treatment Used in the Republic of Moldova
}

\author{
Tudor Lupascu, Igor Povar \\ Institute of Chemistry of the Academy of Sciences of Moldova, Chisinau, Republic of Moldova
}

\author{
Email address: \\ ipovar@yahoo.ca (I. Povar)
}

\section{To cite this article:}

Tudor Lupascu, Igor Povar. Analysis of Adsorption Technologies of Water and Wastewater Treatment Used in the Republic of Moldova. American Journal of Chemical Engineering. Vol. 4, No. 6, 2016, pp. 147-153. doi: 10.11648/j.ajche.20160406.12

Received: October 10, 2016; Accepted: November 8, 2016; Published: November 29, 2016

\begin{abstract}
In this paper, it has been proved that in wastewater purification technology from dyes the adsorption methods ensure practically the complete removal of all dyes. Modified activated carbons, obtained by semi-industrial scale from local renewable raw materials such as cobs, nut shells and grape seeds, have been tested for use in the detoxification technologies of aquatic environment. A significant role in this research is given to adsorption mechanisms of refractory substances on carbon adsorbents. As a result of the physicochemical study of adsorption processes, a scheme of the wastewater purification from dyes has been developed. Their amplified efficiency, in comparison to imported activated carbons, has been demonstrated in experiments, carried out at stations of surface water and groundwater purification, as well as at wastewater treatment plants. At this time, scientific research of the feasibility study and business plan for the economic unit of production of activated carbons, based on local raw materials in the Republic of Moldova, is in progress.
\end{abstract}

Keywords: Activated Carbon, Adsorption, Catalyst, Impregnated Metal Ions, Water Purification

\section{Introduction}

One of the major problems of humanity today is the pollution. It is obvious that the natural environment is deteriorated gradually and ecological systems cannot adapt to the pressure of human activities, the self-regulating of ecosphere becoming increasingly difficult [1]. The primary water pollution, as a result of the direct influx of waste in waters, or their secondary pollution deriving from changes of harmful substances under the action of natural factors, can have multiple effects on environmental components. Shedding untreated waters in the oceans leads also to their pollution [2].

At present, one of the major problems for the environment is wastewater containing organic substances, with aromatic structures, that are bio-non-degradable [3]. For the development of local technologies of the treatment of wastewater, containing detergents and dyes, additional scientific research is necessary.

The most used methods of wastewater treatment with surfactants and dyes are based on their immobilization by adsorption. Activated carbons are most frequently used as adsorbents. This is largely recognized in a number of papers [4-8]. In this case the adsorption process is efficient since the energy of interaction of the organic substances with carbon atoms from activated carbons is greater than the energy of the interaction of water molecules with the carbon atoms on the surface of activated carbons. Activated carbons have a special role in municipal wastewater treatment processes by biological methods $[9,10]$. This is explained by the fact that, after biological treatment of waste waters, compounds biologically non-degradable remain intact. The amount of chemical oxygen demand (COD) of these waters is $60-140 \mathrm{mg}$ $\mathrm{O} / \mathrm{L}$. Using activated carbon adsorbents, $\mathrm{COD}$ value decreases by $10-20 \mathrm{mg} \mathrm{O} / \mathrm{L} \mathrm{[4]}$. The most dangerous, biologically non-degradable, compounds are chemical products which contain the structure of benzene ring and, in particular, phenol, aniline and their derivatives. As mentioned above, for their removal from wastewater activated carbons are used [11]. Developing efficient technologies for wastewater treatment requires research on determining the mechanism of adsorption of the refractory substances on activated carbon [12]. The analysis of literature concerning the use of adsorptive technologies for wastewater treatment shows that for increasing their efficiency it is necessary to remove organic components mostly by chemical and physicochemical methods [4]. One of the most effective methods is the 
coagulation. The salts of iron, aluminum, calcium, or their mixtures are usually used as coagulants [13]. In some cases, the process of electrocoagulation with the aluminum electrode is applied [14]. At present, alongside with coagulation, the process of flocculation with organic polyelectrolytes is used [15].

The main sources of wastewater in the Republic of Moldova are the agricultural processing industry, food industry, electronics, machine building, light industry etc. Currently at stations of surface water purification there are used such preventive procedures as chlorination, coagulation, flocculation, sedimentation, filtration through the quartz substrate and final chlorination. The most effective way of the treatment of wastewater, containing surfactants and dyes, is their immobilization by the adsorption used activated carbons as adsorbents. Recently it is paid a special attention to the use of modified activated carbons, impregnated with metal ions on their surfaces, as they possess twofold role: adsorbent and catalyst.

The analysis of bibliographic sources, concerning the use of activated carbons in wastewater treatment technologies from dyes and surfactants, shows that so far there are not established maximum concentrations of organic substances in wastewater, for which the use of carbon sorbents is economically profitable, as well as the technological processes that allow solving this problem.

Based on the data revealed above, the aim of this paper is the analysis of the efficiency of local technologies for wastewater treatment $[4-8,16]$. The main objective of this paper is to show that in wastewater purification technology from dyes, developed by the authors, the adsorption methods ensure practically the complete removal of all dyes. A significant role in our research is assigned to adsorption mechanisms of refractory substances on carbon adsorbents. By the physicochemical study of the adsorption processes, a scheme of the wastewater purification from dyes will be projected.

\section{Materials and Methods}

Coagulation and sorption processes of textile dyes were studied in model solutions as well as waste water from the dyeing factory "Steaua" ("Star") located in the Chisinau city, the capital of the Republic of Moldova. As flocculants there were used the industrial polyacrylamide and cationic polyelectrolytes obtained at the Institute of Macromolecular Chemistry "P. Poni" in Iasi, Romania. Removal of textile dyes by coagulation was studied using different concentrations of $\mathrm{Al}_{2}\left(\mathrm{SO}_{4}\right)_{3} \cdot 18 \mathrm{H}_{2} \mathrm{O}$ and $\mathrm{Fe}_{2}\left(\mathrm{SO}_{4}\right)_{3} \cdot 9 \mathrm{H}_{2} \mathrm{O}$ - pure for analysis (Merck). Industrial textile dyes contain from 30 to $70 \% \mathrm{NaCl}$. Techniques colorants were purified using the method developed by the authors, which includes the recrystallization of dyes from concentrated solutions of $\mathrm{NaClO}_{4}$ and then separating the dyes from $\mathrm{NaClO}_{4}$ by treatment with anhydrous ethyl alcohol, EtOH. The dyes are insoluble while $\mathrm{NaClO}_{4}$ is soluble in $\mathrm{EtOH}$. The process was repeated until the dye purity of $99.5 \%$ was obtained.
The adsorption processes of dyes were studied on industrial activated carbons of the AC-3 type, manufactured in the Russian Federation.

The adsorption value of dyes on activated carbon AC-3 was established using the relation:

$$
a=\frac{\left(C_{0}-C_{e}\right) * V}{m}
$$

where

$\mathrm{C}_{0}$ - initial concentration of dye, $\mathrm{mmol} / \mathrm{L}$;

$\mathrm{C}_{\mathrm{e}}$ - equilibrium concentration, $\mathrm{mmol} / \mathrm{L}$;

$\mathrm{V}$ - solution volume, $\mathrm{L}$;

$\mathrm{m}$ - mass of activated carbon, $\mathrm{g}$.

The equilibrium concentration of dyes was determined using the UV-VIS spectrophotometer Jenway 6505.

\section{Results and Discussion}

The chemical composition, physical and organoleptic parameters of wastewater from textile factories are presented in Table 1 [17]. The analysis of the data, presented in Table 1, shows that waste waters from dyeing baths fabrics have a high degree of pollution. Synthetic textile dyes and surfactants have as well a harmful action on the activated sludge from biological treatment plants. In order to increase the efficiency of wastewater purification methods by adsorption, the processes of flotation and coagulation should be applied [4, 5, $16]$.

Table 1. The average chemical composition, physical and organoleptic parameters of wastewater from textile factories in the Republic of Moldova.

\begin{tabular}{ll}
\hline Parameters & Values \\
\hline Temperature, ${ }^{\circ} \mathrm{C}$ & $35-45$ \\
$\mathrm{pH}$ & $10-12$ \\
Colour & maroon \\
The degree of dilution until the colour disappeared & $1: 600$ \\
Chemical oxygen demand (COD), mg O2/L (dichromate) & $650-850$ \\
Biological oxygen demand (BOD5), mg O2/L & $250-380$ \\
Concentration of anionic surface-active substances, mg/L & $65-90$ \\
Concentration of non-ionic surface-active substances, mg/L & $50-65$ \\
Direct dyes concentration, mg/L & $46-69$ \\
Active dyes concentration, mg/L & $5-11$ \\
Acid dyes concentration, mg/L & $10-15$ \\
\hline
\end{tabular}

The degree of decrease of organic load and suspended substances in wastewater depends on many factors, such as the quantity of harmful substances in aquatic environment, temperature and ionic strength of the solution etc. Hence, for the development of wastewater treatment technologies, it is necessary to investigate the processes of coagulation and flocculation in real wastewater. For this purpose, the coagulation processes dyes in wastewater from the textile factory Joint-Stock Company (S. A.) "Steaua" from the Chisinau city and related modeling solutions [17] along with the processes for removing suspended substances, derived from plants of ceramic production, were investigated [18]. Aluminum sulphate and iron sulphate (III) as coagulants and industrial product polyacrylamide along with experimental samples of cationic polyelectrolyte, synthesized at the 
Institute of Macromolecular Chemistry "P. Poni" from Iasi, Romania, as flocculants, were used [18, 19]. The aqueous solutions, pattern of wastewater from textile factories, which contained $30 \mu \mathrm{mol} / \mathrm{L}$ of direct, acids and active dyes, were prepared. The coagulant dose was $680 \mathrm{mg} / \mathrm{L}$ for aluminum sulphate and $370 \mathrm{mg} / \mathrm{L}$ for iron sulphate, calculated from the molecular weights of hydrated crystals $\left[\mathrm{Al}_{2}\left(\mathrm{SO}_{4}\right)_{3} \cdot 18 \mathrm{H}_{2} \mathrm{O}\right]$ and $\left[\mathrm{Fe}_{2}\left(\mathrm{SO}_{4}\right)_{3} \cdot 9 \mathrm{H}_{2} \mathrm{O}\right]$. The obtained results are shown in the Tables 2 and 3.

Table 2. The degree of dye removal from aqueous solutions by the use of coagulant $\mathrm{Al}_{2}\left(\mathrm{SO}_{4}\right)_{3} \cdot 18 \mathrm{H}_{2} \mathrm{O}$.

\begin{tabular}{llll}
\hline Dye & Dye concentration after coagulation, $\boldsymbol{\mu m o l} / \mathbf{L}$ & $\mathbf{p H}$ of solution & Degree of removal, \% \\
\hline Direct purple & 0.1 & 6.3 & 99.7 \\
Blue anthraquinone acid & 4.0 & 6.3 & 86.0 \\
Active red 5CX & 22.0 & 6.3 & 26.0 \\
\hline
\end{tabular}

The results presented in Tables 2 and 3 show that during the coagulation process the "direct" dyes almost are completely removed from aqueous solutions. The dyes are removed quite advanced from the acid baths (86-93\%). The active dyes are removed poorly. The same data show that iron (III) hydroxide immobilizes the ions formed by hydrolysis of coagulants more pronounced than aluminum hydroxide. These phenomena can be explained by the fact that active dyes possess weak association properties in aqueous solutions because the dye ions reject each other via their active groups.

Table 3. The degree of dye removal from aqueous solutions by the use of coagulant $\left[\mathrm{Fe}_{2}\left(\mathrm{SO}_{4}\right)_{3} \cdot 9 \mathrm{H}_{2} \mathrm{O}\right]$.

\begin{tabular}{llll}
\hline Dye & Dye concentration after coagulation, $\boldsymbol{\mu m o l} / \mathbf{L}$ & $\mathbf{p H}$ of solution & Degree of removal, \% \\
\hline Direct purple & 0.1 & 4.2 & 98 \\
Blue anthraquinone acid & 2.0 & 4.2 & 93 \\
Active red 5CX & 18.0 & 4.2 & 40 \\
\hline
\end{tabular}

The coagulation processes of organic substances in wastewater of textile enterprises were also examined. The results of investigations on determining the degree of removal of organic load by the coagulation process in wastewater from the Joint-Stock Company (S. A.) "Steaua" are presented in Table 4.

Table 4. The removal degree of the organic load from wastewater of the textile factory S. A. "Steaua".

\begin{tabular}{|c|c|c|c|c|c|c|c|}
\hline \multirow{2}{*}{ Coagulant } & \multirow{2}{*}{$\begin{array}{l}\text { Concentration, } \\
\mathrm{mg} / \mathrm{L}\end{array}$} & \multirow{2}{*}{ Ph of solution } & \multicolumn{2}{|l|}{ Dilution degree } & \multicolumn{2}{|l|}{$\mathrm{COD}, \mathrm{mg} \mathrm{O}_{2} / \mathrm{L}$} & \multirow{2}{*}{$\begin{array}{l}\text { Degree of } \\
\text { removal, \% }\end{array}$} \\
\hline & & & before coagulation & after coagulation & before coagulation & after coagulation & \\
\hline $\mathrm{Al}_{2}(\mathrm{SO} 4)_{3} \cdot 18 \mathrm{H}_{2} \mathrm{O}$ & 680 & 6.3 & $1: 500$ & $1: 50$ & 680 & 256 & 62.3 \\
\hline $\mathrm{Fe}_{2}(\mathrm{SO} 4)_{3} \cdot 9 \mathrm{H}_{2} \mathrm{O}$ & 370 & 4.2 & $1: 500$ & $1: 35$ & 680 & 424 & 37.6 \\
\hline
\end{tabular}

The obtained data show that using coagulation processes of wastewater from textile factories, there can be reduced the organic load by $40-60 \%$ and the intensity of the water color by 10 times. After decanting the residual waters contain about $50 \%$ of organic substances, including active dyes. For total purification of wastewater from organic substances it is necessary to use the process of sorption on various adsorbents, especially, on activated carbons [20-22]. For the feasibility study of wastewater treatment technologies based on the adsorption process, sorption kinetics and dynamics of dyes on activated carbon were investigated. The adsorption kinetics of direct purple on the activated carbon $\mathrm{AC}-3$ and active red $5 \mathrm{CX}$ on the activated carbon $\mathrm{AC}-\mathrm{O}$ have been investigated. To determine the region in which the adsorption rate is governed by internal diffusion, the dependence between the rate of dyes adsorption and the number of rotations of the stirrer in the apparatus of mixing the adsorbent with solution has been examined. The mixing intensity in the apparatus with stirrer is expressed by the modified Reynolds criterion [23]:

$$
R_{e}=n d \rho / \mu
$$

where $n$ is the number of rotations of the stirrer per minute; $d$ is the diameter of the stirrer pallets ring; $\rho$ - water density; $\mu-$ dynamic coefficient of viscosity.

The results on the kinetics of adsorption of the dyes on activated carbons AC-3 and AC-O are depicted in Figures 1 3. As it is shown in Figure 1, for the stirring intensity $R_{e}=41$ 666 , the time to reach of the adsorption equilibrium for direct purple dye is equal to 80 hours. While the Reynolds criterion is rising, the speed of dye adsorption increases (Figure 2).

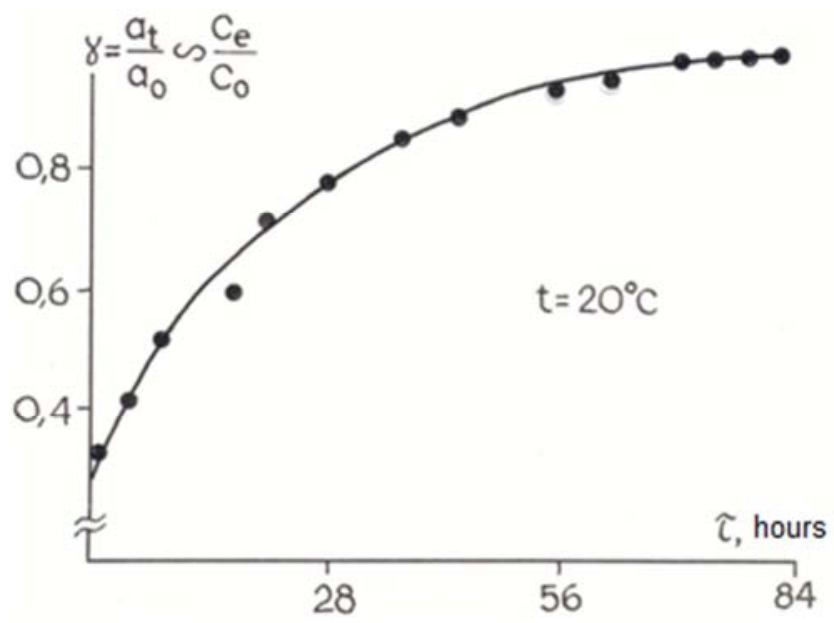

Figure 1. Kinetics of the dye direct purple adsorption on the activated carbon CA-3 (fraction 0.1-0.08 $\mathrm{mm}$ ) at $R_{e}=41666$. 


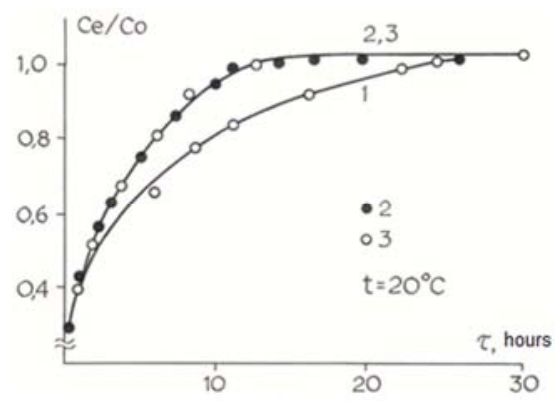

Figure 2. The dependence of the adsorption kinetics of the dye direct purple on the activated carbon $\mathrm{CA}-3$ (0.08 to $0.06 \mathrm{~mm}$ fraction) of $0.1 \mathrm{M} \mathrm{NaCl}$ solution on the stirring intensity: $1-R_{e}=75000 ; 2-R_{e}=100000 ; 3-R_{e}=$ 125000 .

The internal diffusion region of adsorption of the dyes from aqueous solutions on activated carbon AC-3, where the adsorption rate does not depend on the steering intensity, reaches at value $R_{e}=100000$. The time to reach the adsorption equilibrium of the dye direct purple on the activated carbon CA-3 in this case is equal to 15 hours (Figure 2). The kinetics of reaching the adsorption equilibrium depends on the temperature of solution. This can be seen from the results shown in Figure 3. When raising the temperature of the solution from $20^{\circ} \mathrm{C}$ to $40^{\circ} \mathrm{C}$ the speed of reaching the equilibrium of adsorption in the internal diffusion region is reduced approximately two-fold (from 11 to 5 hours).

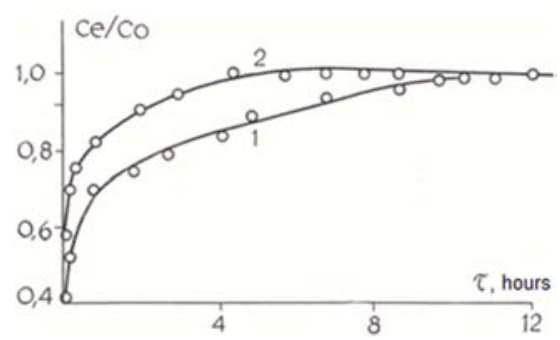

Figure 3. Kinetics of adsorption of dye active red on activated carbon $C A 3$ (0.08 to $0.06 \mathrm{~mm}$ fraction, $\mathrm{Re}=100000)$ in $0.2 \mathrm{M} \mathrm{NaCl}$ solution at different temperatures: $1-20^{\circ} \mathrm{C} ; 2-40^{\circ} \mathrm{C}$.

Next, the dynamics of adsorption of dyes on activated carbon layer was analyzed. The dependence of the working time of the activated carbon layer on the length of the layer at sorption of the dye red $5 \mathrm{CX}$ from aqueous solution, with the dye initial concentration of $10 \mu \mathrm{mol} / \mathrm{dm}^{3}$, is shown in Figure 4.

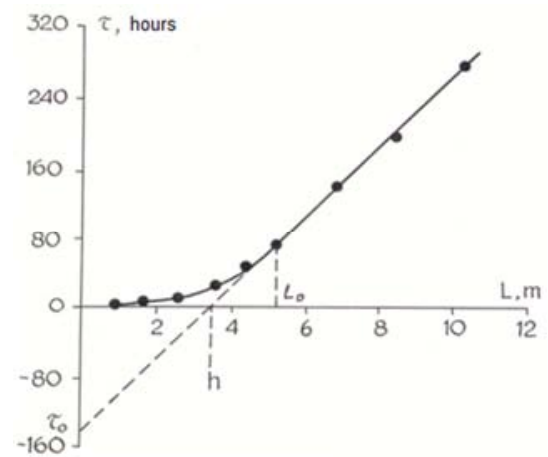

Figure 4. Dependence of the retention time of the active dye red $5 \mathrm{CX}$ on the column length with activated carbon CA-3.
The dyes were dissolved in tap water, which contains cations of $\mathrm{Na}^{+}, \mathrm{K}^{+}, \mathrm{Ca}^{2+}, \mathrm{Mg}^{2+}, \mathrm{Fe}^{3+}$ and anions of $\mathrm{Cl}^{-}, \mathrm{SO}_{4}{ }^{2-}$, $\mathrm{HCO}_{3}^{-}, \mathrm{NO}_{3}^{-}$. The ionic strength of the used water was calculated using the well-known equation:

$$
I=\frac{1}{2} \sum_{i=1}^{n} C_{i} Z_{i}^{2}
$$

where $I$ is the ionic strength of solution, which is $9 \mathrm{mmol} / \mathrm{dm}^{3}$, $C_{i}$ denotes the ion concentration and $Z$ is the ion charge.

According to the Shilov relation for processing of the adsorbent on layers in known conditions, there were established the protective activity coefficient values $K$, the active layer length (length of the exchange mass space) $\mathrm{L}_{\mathrm{o}}$, the length of the unused fraction of layer $h$ and the loss of the time of protection action $\tau_{o}$ [23]. The numerical values of these characteristics were, respectively, equal to $K=38.35 \mathrm{~h} / \mathrm{m}$, $L_{o}=5.25 \mathrm{~m}, h=3.25 \mathrm{~m}, \tau_{o}=128 \mathrm{~h}$.

From the data shown it can be seen that the length of the active layer is greater for adsorption of low molecular weight substances from aqueous solution than from the gaseous medium. This amount (Lo) for adsorption from the gaseous medium is equal to $0.03-0.3 \mathrm{~m}$, while in the case of adsorption from aqueous solutions of substances with low molecular weight Lo is equal to $0.1-1.0 \mathrm{~m}$ [24]. The source of this difference is, on the one hand, the availability of the activated carbon pores is not high, and, on the other hand, the sorption of dye ions by activated carbon goes much slower than adsorption of low molecular weight compounds. From Figure 1 it is clearly seen that, even at a relatively high intensity of agitation of the sorbent solution $(\mathrm{Re}=41666)$, the equilibrium in the adsorption system on the fine coal CA-3 with the 0.1-0.08 mm fraction is achieved within 80 hours. The mass exchange coefficient, as it is known, is inversely proportional to the square of the effective radius of adsorbent granules. Thus, the rate of dye sorption on the granular coal with the granule effective diameter $\approx 1.25 \mathrm{~mm}$ is, at least, 150 times lower than on the coal powder. Since during the adsorption the activated carbon layer is not saturated, the protective activity coefficient calculated from the dynamic data $(K=38.35 \mathrm{~h} / \mathrm{m})$ was found to be much smaller than the coefficient, calculated from the adsorption isotherm, according to the equation:

$$
K=\frac{a_{o} M}{C_{o} W}=\frac{150 \mu \mathrm{mol} / \mathrm{g} \cdot 500 \mathrm{~g} / \mathrm{dm}^{3}}{10 \mu \mathrm{mol} / \mathrm{dm}^{3} \cdot 10 \mathrm{~m} / \mathrm{hour}}=750 \mathrm{~h} / \mathrm{m}
$$

where $a_{o}$ is the specific adsorption of the dye, calculated from the adsorption isotherm at the equilibrium concentration $\mathrm{C}_{\mathrm{e}}{ }_{\mathrm{e}}$, $C_{o}$ is the concentration at the entrance in the block of columns, $\mathrm{W}$ denotes the filtration rate through the layer of activated carbon, $M$ is the mass of activated carbon.

Figures 5 and 6 illustrate dependences of the residual concentration and average specific adsorption of dyes in separate columns of the column block on the time of filtration through the column of the dye solution. 


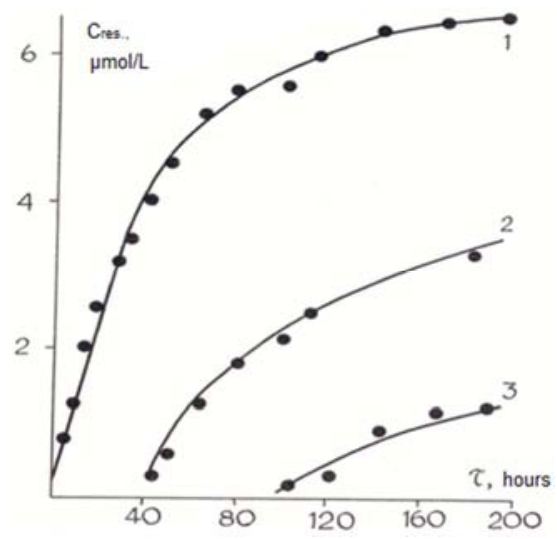

Figure 5. The dependence of the residual concentration (Cres.) of solutions of the active dye red $5 C X$ during their filtration ( $\tau$ ) after exiting the columns: 1 N1 column; 2 - N2 column; 3 - N3 column.

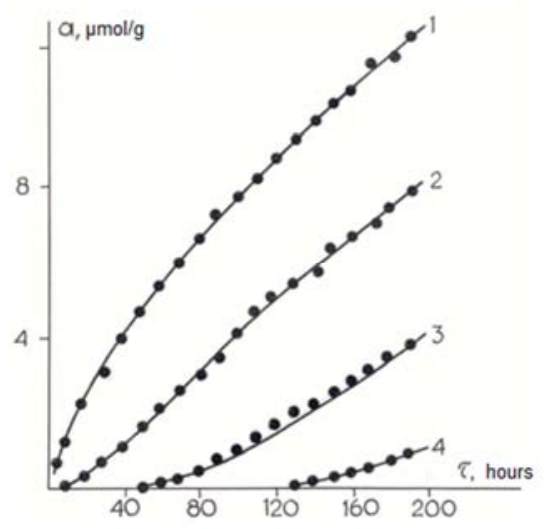

Figure 6. The dependence of the average specific adsorption $(\alpha)$ of the active dye red 5 CX in some columns on the filtration time ( $\tau): 1$ - N1 column; 2 - N2 column; 3 - N3 column; 4-N4 column.
The specific average adsorption in each column was determined from the formula:

$$
\mathrm{a}_{\mathrm{t}}=\frac{\mathrm{W}_{\mathrm{v}}}{\mathrm{m}}\left(\mathrm{C}_{\mathrm{o}} \mathrm{t}-\Delta \mathrm{t} \sum_{\mathrm{i}=1}^{\mathrm{n}} \mathrm{C}_{\mathrm{i}}\right)
$$

where $a_{t}$ is the absorption at the time $t$, in $\mu \mathrm{mol} / \mathrm{g} ; C_{o}$ is the initial concentration in $\mu \mathrm{mol} / \mathrm{dm}^{3} ; C i$ denotes the residual concentration from the column at the time $t$, in $\mu \mathrm{mol} / \mathrm{dm}^{3} ; W_{v}$ is the volumetric filtration rate in $\mathrm{dm}^{3} / \mathrm{h} ; t$ is the filter time, in hours; $m$ is the mass of carbon in the column in $\mathrm{g} ; \Delta t$ symbolizes the time interval between two measurements of residual concentration.

The data of the specific absorption $a_{m}$ of the dye at the moment of its passage through the column N5 and residual concentrations of the dye in solution in the predecessor columns $\left(C_{e}\right)(N 1-N 4)$, which gradually decrease along the sorbent layer in the direction of filtering, are shown in Table 5. From Figures 5, 6 and Table 5 it can be concluded that the overall length of the column block should be much larger than the length of the mass exchange area $L_{o}$. From these data it can be also seen that for the overall length of the carbon layer (at least in excess of 1.5 times than the length of the active portion), its first section of $1.8 \mathrm{~m}$, is soaked to $12 \mu \mathrm{mol} / \mathrm{g}$, while the average load of carbon in the processed layer, calculated from the coefficient of the protective action, according to the equation (4), constitutes $7.5 \mu \mathrm{mol} / \mathrm{g}$. Thus, the layer of processed coal continues to adsorb the dye from solution, e.g. the specific adsorption of the dye within this section, in the case of the adsorption of dyes, is far from equilibrium.

Table 5. Specific adsorption and residual concentration distribution along the block of joined columns (at $L_{o}=5,25 \mathrm{~m}, \mathrm{~K}=38,35 \mathrm{~h} / \mathrm{m}, \tau_{o}=120 \mathrm{hrs}$ ).

\begin{tabular}{llll}
\hline $\begin{array}{l}\text { Column } \\
\text { number }\end{array}$ & Column length, $\mathbf{M}$ & $\begin{array}{l}\text { am of dye in some columns when moving in the } \\
\text { N5 column, } \boldsymbol{\mu m o l} / \mathbf{g}\end{array}$ & $\begin{array}{l}\text { Ce at the exit from column when dye is crossing } \\
\text { through the } \mathbf{N 5} \text { column, } \boldsymbol{\mu m o l}_{\mathbf{m}} \mathbf{\mathbf { d m } ^ { 3 }}\end{array}$ \\
\hline 1 & 1.8 & 12.2 & 6.5 \\
2 & 1.8 & 8.0 & 3.2 \\
3 & 1.7 & 4.0 & 1.2 \\
4 & 1.7 & 1.0 & 0.8 \\
5 & 1.7 & 0.05 & Traces \\
\hline
\end{tabular}

The regeneration of activated carbon is performed not for the whole layer used, but only for a part of it, which falls within the length of exhausted layer. As it is shown in Fig. 4, in the case of the overall length of layer that exceeds $\mathrm{L}_{0}$, the calculation of the length of exhausted layer (L), intended for regeneration, should be performed using the formula:

$$
L=\frac{t}{K}
$$

where: $t$ is the scheduled time between regeneration cycles of the layer portion; $K$ is the coefficient of protective action of the block of columns with activated carbon. The obtained data were used for the purification of wastewater from textile enterprises.

The drainage water from the coloring sections after treatment with aluminum sulfate was filtered through a layer of activated carbon CA-3 with a length of $5.2 \mathrm{~m}$ and a speed of $10 \mathrm{~m} / \mathrm{h}$. The appearance of dyes in solution is observed after 33 hours of filtration through column. Traces of anionic surface-active substances (SAS) are detected in the filtrate after 11 hours. The SAS of non-ionic nature appear in the filtrate after 13 hours. At the moment of dyes passing, the concentration of the SAS anionogene forms is $1.3 \mathrm{mg} / \mathrm{dm}^{3}$, while that of non-ionic forms is $4.7 \mathrm{mg} / \mathrm{dm}^{3}$.

The research of dynamics of adsorption of the dyes in aqueous solution, with a concentration similar to those in the actual wastewater from the dyeing tissues plants through a layer of carbon with a length of $5.2 \mathrm{~m}$, confirmed that traces of the dye amounts are observed after 68 hours of its filtration through column. Therefore, at adsorption of organic impurities from wastewater, a part of the efficient surface of 
activated carbon, accessible to dye ions, is occupied by molecules of other organic compounds, present in wastewater of textile enterprises. As such substances there are present, first of all, the ions and micelles of anionic and non-ionic SAS, which are always present in wastewater of the processing and dying sections of textile factories, which can significantly influence the adsorption of dyes.

Experiments conducted on wastewater purification at the processing and discoloration sections allowed developing and recommending the following schemes of the wastewater purification from dyes (Figure 7).

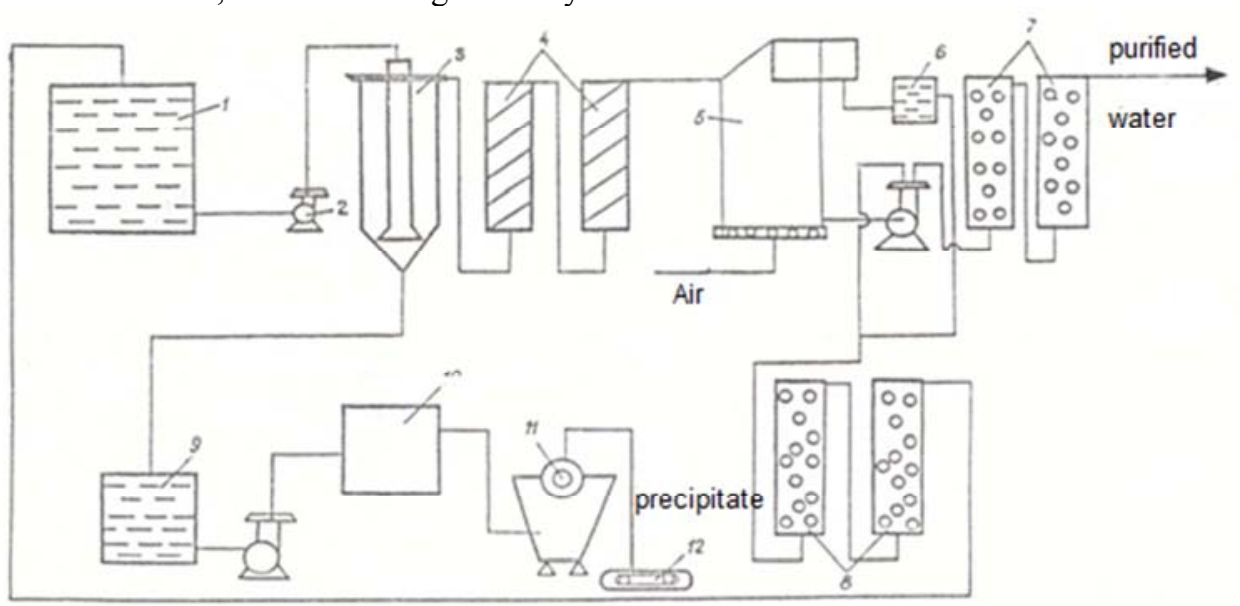

Figure 7. The technological scheme of purification of wastewater from textile factories: 1 - homogenizer; 2 - pump; 3 - vertical tank; 4 - quartz filter; 5 - floats; 6 - foam extinguisher; 7,8 - filters of activated carbon; 9 - precipitate accumulator; 10 - precipitate mixer; 11 - filter with vacuum; 12 - transporter.

In the first purification step the wastewater is treated with coagulants - aluminum sulphate and trivalent iron sulfate. In the use $\mathrm{Al}_{2}\left(\mathrm{SO}_{4}\right)_{3}$ as a coagulant, $\mathrm{pH}$ of solution is adjusted with sodium bicarbonate to the value 5-6, while the use of ferric sulphate as coagulant the $\mathrm{pH}$ should be approximately equal to 4. After entering the coagulant, solution was allowed to sediment precipitate quietly. Then it is passed through sand filters. As a result of water treatment by coagulants from wastewater there were removed practically completely direct dyes and partially acid dyes. The suspended substances from wastewater are also coagulated and precipitated.

After the precipitation of hydroxides of $\mathrm{Al}^{3+}$ or $\mathrm{Fe}^{3+}$ and the filtration of water through sand filters it contains, in particular, active dyes and mixtures of SAS. In order to extract SAS more completely after coagulation, water is passed through flotation installations. Then it is filtered through a block of columns filled with active charcoal. The overall length of the active carbon layer of the block of columns has to be, as it is found in previous studies [21], no less than $5 \mathrm{~m}$. The recommended speed of the filter is $10 \mathrm{~m} / \mathrm{h}$.

As a result of filtration through a long layer of activated carbon, acid and active dyes, as well SAS are released from water. The amount of $\mathrm{COD}(\mathrm{Cr})$ of the water after the adsorption step is reduced to $10 \mathrm{mgO}_{2} / \mathrm{dm}^{3}$. At this stage the purified water can be passed to urban stations of biologic purification. However, it is more reasonable to re-use it for technological purposes.

\section{Conclusions}

It has been proved that in wastewater purification technology from dyes the adsorption methods ensure practically the complete removal of all dyes. The colorless water in many cases can then be used in various technological processes. The adsorption of dyes from aqueous solutions has a number of features for wastewater purification practice. The large size of the ions of dyes and their mutual electrostatic rejection with increasing their concentration in the adsorption area lead to a significant reduction of adsorption kinetics. As a result, the mass exchange area and, therefore, the lengths of the active layer in the adsorption column are higher in the case of the adsorption of dyes, than those of low molecular weight organic substances, which are non-ionized molecules. That is why the specific adsorption of the dyes in treated films cannot be equilibrated and gradually increases over time, independently of the movement of the mass exchange space along the activated carbon layer. As a result of physicochemical study of the adsorption processes, a scheme of the wastewater purification from dyes has been recommended. It can be concluded that modified activated carbons, obtained by semi-industrial scale from local renewable raw materials such as cobs, nut shells and grape seeds, can be successfully used in the detoxification technologies of aquatic environment. They show a high efficiency for purification of wastewater from textile factories.

\section{References}

[1] Tran Ngoc Han, et al., A critical review on characterization strategies of organic matter for wastewater and water treatment processes, Bioresour. Technol., 2015, 193, 523-533. Doi:10.1016/j.biortech. 2015. 06. 091.

[2] Roth, F., Lessa G. C., Wild C., Kikuchi R. K. P., Naumann M. S., Impacts of a high discharge submarine sewage outfall on water quality in the coastal zone of Salvador (Bahia, Brazil), Mar. Pollut. Bull., 2016, 106, 43-48. 
[3] Zhang Yun, et al., Simultaneous determination of 16 polycyclic aromatic hydrocarbons in reclaimed water using solid-phase extraction followed by ultra-performance convergence chromatography with photodiode array detection. J. Sep. Sci.2016. Doi: 10.1002/jssc.201500823.

[4] C. Kaewprasit et al., Quality measurements, J. Cotton Sci., 1998, 2, 164-173.

[5] Cretescu I., Lupascu T. et al., Low-cost sorbents for the removal of acid dyes from aqueous solutions. Process Saf. Environ. Prot., 2016. Doi: http://dx.doi.org/10.1016/j.psep.2016.05.016.

[6] Zinicovscaia I., Mitina T., Lupascu T. et al., Study of chromium adsorption onto activated carbon. Water, Air, Soil Pollut., 2014, $225,1-6$.

[7] Nastas R., Rusu V., Lupascu T., Copper impregnated activated carbon for the treatment of sulphurous waters. Environ. Eng. Manag. J., 2013, 12, 937-942.

[8] Lupascu T., M. Ciobanu, Adsorption of humic acids and of some metal ions from aqueous solutions on activated carbons. Environ. Eng. Manag. J., 2009, 8, 1039-1043.

[9] Mohan Dinesh et al., Organic and inorganic contaminants removal from water with biochar, a renewable, low cost and sustainable adsorbent-a critical review. Bioresour. Technol., 2014, 160, 191-202. Doi:10.1016/j.biortech.2014. 01. 120.

[10] Liao Xiaobin et al. Changes of biomass and bacterial communities in biological activated carbon filters for drinking water treatment. Process Biochem., 2013, 48 (2), 312-316. Doi:10.1016/j.procbio.2012.12.016.

[11] Adebisi Segun Akanmu et al. Equilibrium, Kinetic and Thermodynamics Studies of Adsorption of Aniline Blue from Aqueous Media Using Steam-Activated Carbon Prepared from Delonix regia Pod, J Water Resource Prot., 2015, 7 (15), 1221. Doi:10.4236/jwarp.2015.715099.

[12] Shehzad Areeb et al. An overview of heavily polluted landfill leachate treatment using food waste as an alternative and renewable source of activated carbon. Process Saf. Environ. Prot., 2015, 98, 309-318. Doi: 10.1016/j.psep.2015.09.005.

[13] Lu Rongrong et al. Novel polyaluminum ferric chloride composite coagulant from Bayer red mud for wastewater treatment. Desalin. Water Treat., 2014, 52 (40-42), 7645-7653. Doi: 10.1080/19443994.2013.831791.

[14] YavuzY. et al. Treatment of Basic Red 29 dye solution using iron-aluminum electrode pairs by electrocoagulation and
electro-Fenton methods. Environ. Sci. Pollut. Res., 2014, 21 (14), 8603-8609. Doi: 10.1007/s11356-014-2789-8.

[15] Verma, Akshaya Kumar, Rajesh Roshan Dash, Puspendu Bhunia. A review on chemical coagulation/flocculation technologies for removal of color from textile wastewaters. $J$. Environ. Manag., 2012, $93 \quad$ (1), 154-168. Doi:10.1016/j.jenvman.2011.09.012.

[16] Duca Gh. Management of Water Quality in Moldova. Vol. 69. Springer, 2014.

[17] Lupascu T., The use of activated carbons in wastewater treatment processes dyes, Symposium. Edition IV. Environmental protection - part of the restructuring of the Romanian economy, 1995, 21 - 23 September, Bucharest, 16-19.

[18] Lupascu T., Dranca I., Sandu M., Study of some flocculating processes with cationic Polyelectrolytes, Angew. Makromol. Chem., 1994, 220, 11-19.

[19] S. Dragan et al. Thermal behavior of some cationic polyelectrolytes and polyelectrolyte complexes, Eur. Polym. J., 1998, 34, 733-737.

[20] Timbaliuc N., Lupascu T. The Influence of the porous structure of local activated carbons on the immobilization of the Congo Red dye and vitamin B 12, Chem. J. Mold., 2013, 8 (1), 90-100.

[21] Timbaliuc N., Lupascu T. Use of activated carbon adsorbents for the immobilization of the Congo Red dye. Scientific papers of 14-th International Scientific Conference "Resources of Natural Waters of the Carpathian Region", 28-29 of May, 2015, Lviv, Ukraine, 25-29.

[22] Lupascu T., Povar I. Water and wastewater treatment in the Republic of Moldova. Proceedings of WASTEnet 2015 Scientific Conference "Sustainable Solutions to Wastewater Management: Maximizing the Impact of Territorial Co-Operation", Kavala, Greece, 19th - 21st June, 2015, 70.1-70.09.

[23] Vítěz T., Trávníček P., Study of settling velocity of sand particles located in wastewater treatment plant. Acta Univ. Agric. Silvic. Mendel. Brun. 2014, 59 (1), 249-254. http://dx.doi.org/10.11118/actaun201159010249.

[24] T. Lupascu, Investigation of the dynamics of adsorption of the dye of the active bright red 5 CX on activated carbon AG-3, Proc. Acad. Sci. Moldova, Ser. Biol. Chem. Sci., 1979, 4, 56-59. 